\title{
PENERAPAN METODE TOPSIS DALAM PENENTUAN DOSEN TERBAIK
}

\author{
Gunawan Wibisono ${ }^{1}$, Arif Amrulloh ${ }^{2}$, ElH Ujianto ${ }^{3}$ \\ 19unawan.wibisono@student.uty.ac.id, ${ }^{2}$ arif.amrulloh@student.uty.ac.id, ${ }^{3}$ erik.iman@uty.ac.id \\ 1,2,3Universitas Teknologi Yogyakarta (UTY)
}

\begin{abstract}
Abstrak
Penghargaan terhadap kinerja seorang pekerja sangat penting dalam tujuan untuk menghargai usaha dan jerih payahnya untuk institusi. Dalam dunia pendidikan khususnya perguruan tinggi, dosen merupakan salah satu komponen utama dalam membangun kualitas dan kuantitas. Kualitas dosen yang baik seharusnya akan memberikan kualitas lulusan yang baik pula, sedangkan kuantitas atau jumlah dosenpun akan mempengaruhi jumlah mahasiswa di perguruan tinggi tersebut. Tujuan membangun kualitas dosen, penghargaan dalam bentuk pemeringkatan dosen terbaik dapat menjadi salah satu alternatif pemicu peningkatan kualitas. Sistem pendukung keputusan(SPK) dapat menjadi alat yang membantu pemeringkatan dosen terbaik, tentunya dengan kriteria untuk menghasilkan alternatif peringkat. Lama kerja, prestasi dan tridharma (pengajaran, penelitian, dan pengabdian) perguruan tinggi dijadikan sebagai kriteria untuk mendapatkan alternatif peringkat dosen terbaik dari jumlah dosen sebanyak 20 orang. Data dosen diambil dari program studi teknik telekomunikasi Institut Teknologi Telkom Purwokerto (ITTP). Metode TOPSIS dipilih dalam SPK multikriteria ini, hasilnya adalah 6 orang dosen terpilih untuk menjadi alternatif dosen terbaik dan dari hasil tersebut ternyata yang sangat mempengaruhi adalah jumlah penelitian dan rangking pengajaran, sedangkan lama kerja tidak begitu mempengaruhi.
\end{abstract}

Kata kunci: Sistem Pendukung Keputusan, Dosen Terbaik, ITTP, TOPSIS

\section{Abstract}

Appreciation for the performance of a worker is very important in the aim of valuing his efforts for the institution. In the world of education, especially universities, lecturers are one of the main components in building quality and quantity. The good quality of lecturers should also provide good quality graduates, while the quantity or number of lecturers will affect the number of students in the college. In the aim of building the quality of lecturers, the award in the form of ranking the best lecturers can be an alternative trigger for quality improvement. Decision support systems (DSS) can be a tool that helps rank the best lecturers, of course with criteria to produce ranking alternatives. The length of work, achievements and tridharma (teaching, research, and consecration) of higher education is used as a criterion to obtain the best alternative rank of lecturers from the number of lecturers as many as 20 people. Lecturer data is taken from the telecommunication engineering study program Institut Teknologi Telkom Purwokerto (ITTP). The TOPSIS method was chosen in this multicriteria DSS, the result was 6 selected lecturers to be the best alternative lecturers and from these results it turned out that the most influential was the number of research and teaching rankings, while the duration of work did not affect much.

Keywords: Decision Support System, The Best Lecturer, ITTP, TOPSIS

\section{Pendahuluan}

Penghargaan merupakan imbalan yang diberikan oleh perusahaan terhadap karyawannya atas pekerjaan yang telah dilakukannya, baik penghargaan yang bersifat intriksik ataupun ekstrinsik [1]. Dalam dunia pendidikan khususnya perguruan tinggi dosen selain sebagai tenaga pengajar juga merupakan karyawan dari sebuah institusi perguruan tinggi, dimana salah satu tugas seorang dosen adalah melakukan Tridharma Perguruan Tinggi, menurut UU Nomor 12 Tahun 2012 Tentang Pendidikan Tridharma Perguruan Tinggi yang selanjutnya disebut Tridharma adalah kewajiban Perguruan Tinggi untuk menyelenggarakan Pendidikan, penelitian, dan pengabdian kepada masyarakat [2].

Perguruan tinggi dianggap baik jika mampu memberikan hasil yang baik pula terhadap Tridharma, oleh karena itu dibutuhkan kinerja yang baik dalam pencapaiannya. Peningkatan kinerja dapat dilakukan dengan cara studi lanjut, pelatihan, penilaian dan penghargaan. Dosen sebagai salah satu komponen dalam perguruan tinggi merupakan komponen pokok yang dapat menentukan kualitas 
ILKOM Jurnal Ilmiah Volume 11 Nomor 2 Agustus 2019 Terakreditasi peringkat 3 SK. No. 28/E/KPT/2019

peserta didik selain dengan adanya aturan dan standarisasi dari perguruan tinggi itu sendiri. Hal tersebut merupakan salah satu alasan dimana kinerja dosen perlu dijaga dan selalu ditingkatkan.

Penghargaan dapat dijadikan sebagai sarana dalam memicu peningkatan terhadap kinerja, penghargaan terhadap kinerja dosen dapat dinilai melalui komponen Tridharma, prestasi dan lama kerja dari dosen tersebut di perguruan tinggi sebagai bentuk loyalitas terhadap institusi. Penentuan dosen terbaik adalah salah satu cara dalam memberikan penghargaan, diperlukan metode tertentu dalam proses penentuan ini agar sistematika dapat dipahami dan terbuka bagi seluruh dosen, sehingga masing masing dosen dapat menghitung sendiri dan memvalidasi hasilnya dan pada akhirnya sistematika perhitungan ini dapat memberikan pendukung keputusan dalam penentuan dosen terbaik dengan proses perhitungan yang obyektif.

Sistem Pendukung Keputusan (SPK) multikriteria perlu digunakan dalam menentukan dosen terbaik berdasarkan kriteria yang telah ditentukan, metode TOPSIS merupakan salah satu metode yang digunakan dalam SPK multikriteria. Penelitian yang dilakukan oleh Windarto (2017) menyatakan bahwa metode TOPSIS lebih tepat digunakan dalam menentukan penerima reward dibandingkan dengan metode Simple Additive Weighting (SAW) [3], sedangkan Riandari, et al (2017) menyatakan bahwa penerapan metode topsis telah berhasil dalam pemilihan kepala departemen dengan penentuan kriteria sebagai acuan pengambilan keputusan[4]. Selain itu metode TOPSIS juga berhasil dalam menentukan prioritas kondisi rumah [5], menentukan wilayah promosi penerimaan siswa baru [6] dan penilaian kinerja dosen [7].

Tujuan penelitian ini adalah membuat sistematika dalam penentuan dosen terbaik, dimana prosesnya adalah dengan menentukan kriteria yang relevan terhadap kinerja dosen, proses penghitungan dengan metode TOPSIS, dan hasil dengan beberapa alternatif. TOPSIS dipilih karena beberapa kelebihannya, antara lain konsep yang sederhana dan mudah dipahami, komputasi yang efisien, dan memiliki kemampuan untuk mengukur kinerja relatif dari alternatif alternatif keputusan dalam bentuk matematis sederhana [8]. Penelitian ini dilakukan pada Program Studi Teknik Telekomunikasi Fakultas Teknik Telekomunikasi dan Elektro Institut Teknologi Telkom Purwokerto Tahun 2018.

\section{Metode}

\subsection{Sistem Pendukung Keputusan (SPK)}

Sistem pendukung keputusan sebagai sistem berbasis komputer yang terdiri dari 3 komponen yang saling berinteraksi, sistem bahasa (mekanisme untuk memberikan komunikasi antara pengguna dan komponen sistem pendukung keputusan lain), sistem pengetahuan (repositori pengetahuan domain masalah yang ada pada sistem pendukung keputusan atau sebagai data atau sebagai prosedur), dan sistem pemrosesan (hubungan antara dua komponen lainnya, terdiri dari satu atau lebih kapabilitas manipulasi masalah umum yang diperlukan untuk pengambilan keputusan) [9]. SPK adalah sub koleksi sistem manajemen informasi yang membantu perencana, analis, dan manager atau pengelola dalam proses pengambilan keputusan. Sistem ini dapat memberikan konsep yang berbeda dari pengambilan keputusan dan status pengambilan keputusan yang berbeda [10].

\subsection{TOPSIS}

Technique for Order Preference by Similarity to Ideal Positif merupakan salah satu metode pengambilan keputusan yang dikembangkan oleh Yonn dan Hwang pada 1981. Dalam metode TOPSIS dikenal 2 macam solusi yaitu solusi ideal positif dan solusi ideal negatif. Dengan pertimbangan 2 solusi tersebut membuat ide dasar dari metode ini adalah mencari alternatif terbaik yakni alternatif yang mempunyai jarak terkecil dari solusi ideal positif dan jarak terbesar dari solusi ideal negatif dari sudut pandang geometris dengan menggunakan jarak Euclidean untuk menentukan kedekatan relatif suatu alternatif terhadap solusi optimal [11] .

Langkah langkah dalam metode TOPSIS adalah sebagai berikut [12] :

a. Menentukan matriks keputusan yang ternormalisasi, hasil perhitungan akar kuadrat dari nilai masing masing matrik keputusan.

$$
r_{i j}=\frac{X_{i j}}{\sqrt{\sum_{i=1}^{m} x_{i j}^{2}}}
$$

b. Menghitung matrik keputusan yang ternormalisasi berbobot, perhitungan matrik ternormalisasi dikalikan dengan bobot masing masing kriteria.

$$
\begin{aligned}
& W=W_{1}, W_{2}, W_{3}, \ldots, W_{n} \\
& Y_{i j}=W_{j} \cdot r_{i j}
\end{aligned}
$$


c. Menghitung matrik solusi ideal positif dan solusi ideal negatif.

$$
\begin{aligned}
& A^{+}=\left(Y_{1}^{+}, Y_{2}^{+}, \ldots, Y_{n}^{+}\right) \\
& A^{-}=\left(Y_{1}^{-}, Y_{2}^{-}, \ldots, Y_{n}^{-}\right)
\end{aligned}
$$

d. Menghitung jarak antara nilai setiap alternatif dengan matrik solusi ideal positif dan matrik solusi ideal negatif.

$$
\begin{aligned}
& D_{i}^{+}=\sqrt{\sum_{j=1}^{n}\left(Y_{i}^{+}-Y_{i j}\right)^{2}} \\
& D_{i}^{-}=\sqrt{\sum_{j=1}^{n}\left(Y_{i j}-Y_{i}^{-}\right)^{2}}
\end{aligned}
$$

e. Menentukan nilai reference untuk setiap alternatif $(\mathrm{Vi})$.

$$
V_{i}=\frac{D_{i}^{+}}{D_{i}^{-}+D_{i}^{+}}
$$

f. Nilai Vi yang lebih besar menunjukkan alternatif Ai lebih dipilih.

\subsection{ITTP}

Dalam penelitian ini peneliti mengambil lokasi di Institut Teknologi Telkom Purwokerto (ITTP), perguruan tinggi dengan konsentrasi dalam bidang teknik dibawah naungan Yayasan Pendidikan Telkom dan sudah berumur 17 tahun. Saat ini ITTP mempunyai 2 fakultas dengan 8 program studi dengan mahasiswa lebih dari 2000 orang dan dosen lebih dari 100 orang. Program studi yang dianggap cikal bakal adalah program studi Teknik Telekomunikasi yang merupakan bidang dengan peminat paling banyak. Peneliti menggunakan program studi Teknik Telekomunikasi sebagai objek penelitian dengan jumlah dosen sebanyak 20 orang.

Peneliti menentukan kriteria sebanyak 5, yaitu Lama Kerja, Prestasi, Pengajaran, Penelitian, dan Pengabdian selama tahun 2018. Pengumpulan data dalam penelitian ini menggunakan Data didapat dari berbagai bagian antara lain sumber daya manusia (SDM) untuk data lama kerja dan prestasi, Lembaga Penelitian dan Pengabdian Masyarakat (LPPM) untuk data penelitian dan pengabdian serta Satuan Penjaminan Mutu (SPM) untuk data pengajaran.

Bobot masing masing kriteria didapatkan setelah wawancara dengan staf SPM, dengan penjelasan sebagai berikut:

a. Faktor lama kerja (K1) dosen terhitung semenjak dosen tersebut aktif menjalankan tri dharma perguruan tinggi yaitu pengajaran, penelitian dan pengabdian masyarakat, rentang lama kerja dihitung dengan pertimbangan lama institusi berdiri dibagi lima, dengan nilai bobot (10).

b. Faktor prestasi (K2) yang pernah diraih oleh dosen dalam kurun waktu yang sudah di tetapkan, yang dikategorikan kedalam prestasi antara lain penelitian atau karya yang pernah dilombakan dan keluar sebagai juara dan jurnal yang terindex scopus, dengan nilai bobot (20).

C. Faktor pengajaran (K3) dalam satu semester dihitung dari banyaknya jumlah kehadiran pada setiap matakuliah yang diampu dan hasil survei dari mahasiswa / peserta perkuliahan dosen tersebut, dengan nilai bobot (30).

d. Faktor penelitian (K4) dihitung dari banyaknya penelitian yang dilakaukan baik penelitian individu maupun kelompok, dan seberapa besar efek penelitian terhadap institusi maupun terhadap target dari penelitian tersebut, dengan nilai bobot (25).

e. Faktor pengabdian masyarakat (K5) dihitung dari seberapa sering melakukan pengabdian kepada masyarakat, dengan nilai bobot (15).

Penentuan dosen terbaik berdasarkan kinerja selama tahun 2018 sehingga dosen yang berhak masuk dalam penilaian adalah dosen yang sudah bergabung atau bekerja sampai dengan bulan Desember 2018. Lama kerja dihitung sampai tahun 2018, prestasi selain diambil dari hasil kompetisi yang pernah dilakukan dosen di luar lingkungan kampus juga diambil dari hasil penelitian yang pernah diterbitkan dalam jurnal atau prosiding yang bersifat internasional. Pengajaran diambil dari raport kinerja dosen yang salah satu dasar penilaiannya adalah dari mahasiswa melalui kuisioner, penelitian diambil dari hasil penelitian yang pernah dilakukan oleh dosen dan sudah terbit baik di jurnal maupun di prosiding, pengabdian diambil dari peran dosen dalam kegiatan pengabdian masyarakat. 
ILKOM Jurnal Ilmiah Volume 11 Nomor 2 Agustus 2019

Terakreditasi peringkat 3 SK. No. 28/E/KPT/2019

\section{Hasil dan Pembahasan}

Data dosen yang digunakan sebanyak 20 orang akan menjadi alternatif dengan menggunakan 5 kriteria yang selanjutnya akan diolah menjadi sebuah matrik. Alternatif dan kriteria dijelaskan pada tabel 1 berikut ini :

\begin{tabular}{cc}
\hline No. & Kode Dosen \\
\hline 1 & ARD \\
2 & ANP \\
3 & AFI \\
4 & BGA \\
5 & DPO \\
6 & DZN \\
7 & FTS \\
8 & IMP \\
9 & JGG \\
10 & KNH \\
\hline
\end{tabular}

Tabel 1. Alternatif

\begin{tabular}{cc}
\hline No. & Kode Dosen \\
\hline 11 & KNO \\
12 & PYO \\
13 & RWI \\
14 & RTO \\
15 & SRA \\
16 & SPO \\
17 & RSO \\
18 & SLR \\
19 & UMR \\
20 & ZHP \\
\hline
\end{tabular}

Tabel 2. Kriteria dan Bobot

\begin{tabular}{ccc}
\hline $\begin{array}{c}\text { Kode } \\
\text { Kriteria }\end{array}$ & Kriteria & Bobot \\
\hline K1 & Lama Kerja & 10 \\
K2 & Prestasi & 20 \\
K3 & Pengajaran & 30 \\
K4 & Penelitian & 25 \\
K5 & Pengabdian & 15 \\
\hline
\end{tabular}

Tabel 3. Klasifikasi Lama Kerja

\begin{tabular}{cc}
\hline Nilai & Rentang \\
\hline 1 & $0-3$ tahun \\
2 & Lebih dari $3-6$ tahun \\
3 & Lebih dari $6-9$ tahun \\
4 & Lebih dari $9-11$ tahun \\
5 & Lebih dari 11 tahun \\
\hline
\end{tabular}

Tabel 4. Klasifikasi Pengajaran

\begin{tabular}{cc}
\hline Nilai & Rentang \\
\hline 1 & $0-20 \%$ \\
2 & Lebih dari $20 \%-40 \%$ \\
3 & Lebih dari $40 \%-60 \%$ \\
4 & Lebih dari $60 \%-80 \%$ \\
5 & Lebih dari $80 \%-100 \%$ \\
\hline
\end{tabular}


ILKOM Jurnal Ilmiah Volume 11 Nomor 2 Agustus 2019

Terakreditasi peringkat 3 SK. No. 28/E/KPT/2019

Dari alternatif, kriteria dan aturan pemberian bobot tersebut kemudian dilakukan perhitungan sesuai dengan tahapan pada metode TOPSIS sebagai berikut :

a. Menentukan matrik keputusan ternormalisasi

Matrik keputusan pada Tabel 5 dibangun dengan cara memasukan semua kode dosen diikuti dengan nilai masing masing kriteria yang sudah ditentukan (K1 - K5). Pada Tabel 6. Adalah akar kuadrat dari masing masing kriteria dimana angka ini yang nantinya digunakan dalam membangun matrik keputusan ternormalisasi yagn disajikan pada Tabel 7 .

Tabel 5. Matriks Keputusan

\begin{tabular}{cccccc}
\hline Kode Dosen & K1 & K2 & K3 & K4 & K5 \\
\hline ARD & 2 & 2 & 4 & 4 & 0 \\
ANP & 1 & 0 & 5 & 0 & 0 \\
AFI & 5 & 3 & 5 & 4 & 0 \\
BGA & 1 & 0 & 5 & 4 & 1 \\
DPO & 2 & 0 & 5 & 2 & 0 \\
DZN & 2 & 1 & 5 & 14 & 1 \\
FTS & 2 & 0 & 5 & 2 & 0 \\
IMP & 3 & 0 & 5 & 2 & 0 \\
JGG & 1 & 0 & 5 & 0 & 0 \\
KNH & 1 & 0 & 5 & 0 & 0 \\
KNO & 1 & 0 & 5 & 5 & 2 \\
PYO & 1 & 0 & 5 & 0 & 0 \\
RWI & 1 & 0 & 5 & 0 & 0 \\
RTO & 2 & 1 & 5 & 2 & 1 \\
SRA & 1 & 0 & 5 & 0 & 0 \\
SPO & 2 & 1 & 4 & 0 & 0 \\
RSO & 1 & 0 & 5 & 0 & 0 \\
SLR & 1 & 0 & 5 & 0 & 0 \\
UMR & 1 & 0 & 5 & 1 & 0 \\
ZHP & 2 & 0 & 5 & 2 & 0 \\
\hline
\end{tabular}

Tabel 6. Akar Kuadrat Matrik Keputusan

\begin{tabular}{ccccc}
\hline K1 & K2 & K3 & K4 & K5 \\
\hline 8,71779789 & 4 & 21,9545 & 16,91153 & 2,645751 \\
\hline
\end{tabular}

Tabel 7. Matrik Keputusan Ternormalisasi

\begin{tabular}{crrrrr}
\hline Kode Dosen & K1 & K2 & K3 & K4 & K5 \\
\hline ARD & 0,22941573 & 0,5 & 0,182195 & 0,236525 & 0 \\
ANP & 0,11470787 & 0 & 0,227744 & 0 & 0 \\
AFI & 0,57353933 & 0,75 & 0,227744 & 0,236525 & 0 \\
BGA & 0,11470787 & 0 & 0,227744 & 0,236525 & 0,377964 \\
DPO & 0,22941573 & 0 & 0,227744 & 0,118262 & 0 \\
DZN & 0,22941573 & 0,25 & 0,227744 & 0,827837 & 0,377964 \\
FTS & 0,22941573 & 0 & 0,227744 & 0,118262 & 0 \\
IMP & 0,3441236 & 0 & 0,227744 & 0 & 0 \\
JGG & 0,11470787 & 0 & 0,227744 & 0 & 0 \\
KNH & 0,11470787 & 0 & 0,227744 & 0 & 0 \\
KNO & 0,22941573 & 0 & 0,227744 & 0,295656 & 0,755929 \\
PYO & 0,11470787 & 0 & 0,227744 & 0 & 0 \\
RWI & 0,11470787 & 0 & 0,227744 & 0 & 0 \\
RTO & 0,22941573 & 0,25 & 0,227744 & 0,118262 & 0,377964 \\
SRA & 0,11470787 & 0 & 0,227744 & 0 & 0 \\
SPO & 0,22941573 & 0,25 & 0,182195 & 0 & 0 \\
RSO & 0,11470787 & 0 & 0,227744 & 0 & 0 \\
SLR & 0,11470787 & 0 & 0,227744 & 0 & 0 \\
UMR & 0,11470787 & 0 & 0,227744 & 0,059131 & 0 \\
ZHP & 0,22941573 & 0 & 0,227744 & 0,118262 & 0 \\
\hline
\end{tabular}


ILKOM Jurnal Ilmiah Volume 11 Nomor 2 Agustus 2019

Terakreditasi peringkat 3 SK. No. 28/E/KPT/2019

b. Menghitung matrik keputusan ternormalisasi berbobot

Pada Tabel 8. disusun matrik keputusan terbobot yang merupakan hasil perhitungan dari matrik ternormalisasi dikalikan dengan bobot masing masing kriteria yang sudah ditentukan sebelumnya.

Tabel 8. Matrik Keputusan Berbobot

\begin{tabular}{ccrrrr}
\hline Kode Dosen & K1 & K2 & K3 & \multicolumn{1}{c}{ K4 } & K5 \\
\hline ARD & 2,29415734 & 10 & 5,46585 & 5,913124 & 0 \\
ANP & 1,14707867 & 0 & 6,832313 & 0 & 0 \\
AFI & 5,73539335 & 15 & 6,832313 & 5,913124 & 0 \\
BGA & 1,14707867 & 0 & 6,832313 & 5,913124 & 5,669467 \\
DPO & 2,29415734 & 0 & 6,832313 & 2,956562 & 0 \\
DZN & 2,29415734 & 5 & 6,832313 & 20,69593 & 5,669467 \\
FTS & 2,29415734 & 0 & 6,832313 & 2,956562 & 0 \\
IMP & 3,44123601 & 0 & 6,832313 & 0 & 0 \\
JGG & 1,14707867 & 0 & 6,832313 & 0 & 0 \\
KNH & 1,14707867 & 0 & 6,832313 & 0 & 0 \\
KNO & 2,29415734 & 0 & 6,832313 & 7,391405 & 11,33893 \\
PYO & 1,14707867 & 0 & 6,832313 & 0 & 0 \\
RWI & 1,14707867 & 0 & 6,832313 & 0 & 0 \\
RTO & 2,29415734 & 5 & 6,832313 & 2,956562 & 5,669467 \\
SRA & 1,14707867 & 0 & 6,832313 & 0 & 0 \\
SPO & 2,29415734 & 5 & 5,46585 & 0 & 0 \\
RSO & 1,14707867 & 0 & 6,832313 & 0 & 0 \\
SLR & 1,14707867 & 0 & 6,832313 & 0 & 0 \\
UMR & 1,14707867 & 0 & 6,832313 & 1,478281 & 0 \\
ZHP & 2,29415734 & 0 & 6,832313 & 2,956562 & 0 \\
\hline
\end{tabular}

c. Menghitung matrik solusi ideal positif dan matrik solusi ideal negatif

Matrik solusi ideal positif didapatkan dari nilai maksimal (tertinggi) masing masing kriteria dari matrik keputusan berbobot, sebaliknya untuk matrik solusi ideal negatif didapatkan dari nilai minimal (terendah) masing masing kriteria dari matrik keputusan berbobot, hasilnya ada pada Tabel 9.

Tabel 9. Matrik Solusi Ideal Positif dan Solusi Ideal Negatif

\begin{tabular}{l|rrrrr}
\hline \multirow{4}{*}{$\mathrm{A}+$} & $\mathrm{K} 1$ & $\mathrm{~K} 2$ & \multicolumn{1}{c}{ K3 } & \multicolumn{1}{c}{ K4 } & \multicolumn{1}{c}{ K5 } \\
\cline { 2 - 6 } $\mathrm{A}-$ & 5,73539335 & 15 & 6,832313 & 20,69593 & 11,33893 \\
\hline
\end{tabular}

d. Menghitung jarak antara nilai setiap alternatif dengan matrik solusi ideal positif dan matrik solusi ideal negatif.

Jarak alternatif dengan matrik solusi positif dan negatif adalah perhitungan akar kuadrat dari matrik solusi positif atau negatif dengan matrik ternormalisasi berbobot, ditunjukan pada Tabel 10.

Tabel 10. Jarak Alternatif Matrik Solusi Ideal Positif dan Solusi Ideal Negatif

\begin{tabular}{crl}
\hline Kode dosen & \multicolumn{1}{c}{ D+ } & D- \\
\hline ARD & 19,6421 & 11,67394 \\
ANP & 28,3363 & 1,366463 \\
AFI & 18,6307 & 16,81918 \\
BGA & 22,28737 & 8,305126 \\
DPO & 26,0787 & 3,453153 \\
DZN & 11,99937 & 22,10537 \\
FTS & 26,0787 & 3,453153
\end{tabular}


ILKOM Jurnal Ilmiah Volume 11 Nomor 2 Agustus 2019

Terakreditasi peringkat 3 SK. No. 28/E/KPT/2019

\begin{tabular}{lrr}
\hline IMP & 28,05631 & 2,670277 \\
JGG & 28,3363 & 1,366463 \\
KNH & 28,3363 & 1,366463 \\
KNO & 20,34337 & 13,65237 \\
PYO & 28,3363 & 1,366463 \\
RWI & 28,3363 & 1,366463 \\
RTO & 21,41659 & 8,310663 \\
SRA & 28,3363 & 1,366463 \\
SPO & 25,89599 & 5,129892 \\
RSO & 28,3363 & 1,366463 \\
SLR & 28,3363 & 1,366463 \\
UMR & 27,2753 & 2,013091 \\
ZHP & 26,0787 & 3,453153 \\
\hline
\end{tabular}

e. Menentukan nilai reference untuk setiap alternatif (Vi).

Nilai reference dari masing masing alternatif didapatkan dari nilai jarak solusi negatif dibagi dengan jumlah nilai jarak solusi positif ditambah nilai jarak solusi negatif masing masing kode dosen.

Tabel 11. Nilai Reference Alternatif

\begin{tabular}{cc}
\hline Alternatif & Vi \\
\hline ARD & 12,27 \\
ANP & 1,41 \\
AFI & 17,72 \\
BGA & 8,68 \\
DPO & 3,59 \\
DZN & 23,95 \\
FTS & 3,59 \\
IMP & 2,77 \\
Alternatif & Vi \\
JGG & 1,41 \\
KNH & 1,41 \\
KNO & 14,32 \\
PYO & 1,41 \\
RWI & 1,41 \\
RTO & 8,70 \\
SRA & 1,41 \\
SPO & 5,33 \\
RSO & 1,41 \\
SLR & 1,41 \\
UMR & 2,09 \\
ZHP & 3,59 \\
\hline
\end{tabular}

f. Nilai Vi yang lebih besar menunjukkan alternatif Ai lebih dipilih. 
ILKOM Jurnal Ilmiah Volume 11 Nomor 2 Agustus 2019 Terakreditasi peringkat 3 SK. No. 28/E/KPT/2019

Nilai Vi yang terbesar ke terkecil digunakan dalam pemberian ranking, pada Tabel 12. disusun ranking dosen untuk 6 terbaik.

Tabel 12. Rangking Nilai Vi

\begin{tabular}{ccc}
\hline Ranking & Alternatif & Vi \\
\hline 1 & DZN & 23,95 \\
2 & AFI & 17,72 \\
3 & KNO & 14,32 \\
4 & ARD & 12,27 \\
5 & RTO & 8,70 \\
6 & BGA & 8,68 \\
\hline
\end{tabular}

\section{Kesimpulan dan Saran}

Sistem pendukung keputusan dalam penentuan dosen terbaik menggunakan metode TOPSIS diperolehlah 6 rangking tertinggi dengan hasil masing-masing yang berbeda. Dalam hasil ini juga diperoleh bahwa lama kerja tidak berpengaruh besar terhadap perhitungan dosen berprestasi akan tetapi kriteria penelitian sangat berpengaruh besar terhadap penghitungan dosen berprestasi walaupun bobotnya lebih kecil dari kriteria pengajaran. Hasil akhir ini dapat digunakan sebagai rekomendasi dalam pembuatan keputusan terkait penentuan dosen terbaik dengan kinerja selama 1 tahun.

\section{Daftar Pustaka}

[1] A. S. Prabu and D. T. Wijayanti, "Pengaruh Penghargaan dan Motivasi Terhadap Kinerja Karyawan (Studi Pada Divisi Penjualan PT. United Motors Center Suzuki Ahmad Yani, Surabaya)," J. Ekon. Bisnis dan Kewirausahaan, vol. 5, no. 2, p. 104, Aug. 2016.

[2] P. R. Indonesia, "UNDANG UNDANG NOMOR 12 TENTANG PENDIDIKAN TINGGI PASAL 1 AYAT 9," 2012, 2012. [Online]. Available: http://sumberdaya.ristekdikti.go.id/wpcontent/uploads/2016/02/uu-nomor-12-tahun-2012-ttg-pendidikan-tinggi.pdf. [Accessed: 18May-2019].

[3] A. P. Windarto, "IMPLEMENTASI METODE TOPSIS DAN SAW DALAM MEMBERIKAN REWARD PELANGGAN," KLIK - Kumpul. J. ILMU Komput., vol. 4, no. 1, p. 88, Mar. 2017.

[4] F. Riandari, P. M. Hasugian, and I. Taufik, "SISTEM PENDUKUNG KEPUTUSAN MENGGUNAKAN METODE TOPSIS DALAM MEMILIH KEPALA DEPARTEMEN PADA KANTOR BALAI WILAYAH SUNGAI SUMATERA II MEDAN," J. Inform. Pelita Nusant., vol. 2, no. 1, pp. 6-13, 2017.

[5] A. A. Chamid, "PENERAPAN METODE TOPSIS UNTUK MENENTUKAN PRIORITAS KONDISI RUMAH," Simetris J. Tek. Mesin, Elektro dan IImu Komput., vol. 7, no. 2, p. 537, Nov. 2016.

[6] I. A. Nata, B. Soedijono, and H. Al Fatta, "PENENTUAN WILAYAH PROMOSI PENERIMAAN SISWA BARU DENGAN METODE TOPSIS," J. IIm. Teknol. Inf., vol. 12, no. 34, pp. 61-80, 2017.

[7] C. Surya, "Penilaian Kinerja Dosen Menggunakan Metode TOPSIS (Studi Kasus : Amik Mitra Gama)," J. RESTI (Rekayasa Sist. dan Teknol. Informasi), vol. 2, no. 1, pp. 322-329, May 2018.

[8] Turban E, Aronson JE \& Liang Ting-Peng, Decision Support Systems and Inteligent Systems, Internasional Edition, Edisi 7, New Jersey, 2005

[9] D. Nofriansyah, Konsep Data Mining VS Sistem Pendukung Keputusan, Pertama. Yogyakarta: Deepublish, 2014.

[10] N. G. Khodashahri and M. M. H. Sarabi, "DECISION SUPPORT SYSTEM (DSS)," Singaporean J. Bus. Econ. Manag. Stud., vol. 1, no. 6, pp. 95-102, 2018.

[11] Diana, METODE DAN APLIKASI SISTEM PENDUKUNG KEPUTUSAN, Pertama. Yogyakarta: Deepublish, 2018.

[12] Darsono Nababan and Robbi Rahim, "Sistem Pendukung Keputusan Reward Bonus Karyawan Dengan Metode Topsis," Simetris, vol. 3, no. 6, pp. 2-6, 2018. 